\title{
Risk factors for atherosclerosis and vascular calcification in patients with type 2 diabetes on long-term hemodialysis
}

\author{
Tatyana Archakova, Liudmila Nedosugova \\ Endocrinology Department, Medical Faculty, I.M. Sechenov First Moscow State Medical University, Moscow 119991, Russia.
}

Correspondence to: Dr. Liudmila Nedosugova, Endocrinology Department, Medical Faculty, I.M. Sechenov First Moscow State Medical University, Moscow 119991, Russia. E-mail: profmila@mail.ru

How to cite this article: Archakova T, Nedosugova L. Risk factors for atherosclerosis and vascular calcification in patients with type 2 diabetes on long-term hemodialysis. Vessel Plus 2018;2:34. http://dx.doi.org/10.20517/2574-1209.2018.52

Received: 8 Jul 2018 First Decision: 28 Aug 2018 Revised: 5 Sep 2018 Accepted: 10 Sep 2018 Published: 26 Oct 2018

Science Editor: Igor A. Sobenin Copy Editor: Cui Yu Production Editor: Zhong-Yu Guo

\begin{abstract}
Type 2 diabetes mellitus (DM) is a risk factor for the progression of cardiovascular mortality, exacerbated by the development of chronic renal failure secondary to diabetic nephropathy, which requires long-term hemodialysis (LTH). However, in the case of LTH cardiovascular mortality exceeds that in the general population, especially in patients with diabetes. The identification of risk factors for the progression of atherosclerosis and vascular calcification in patients with DM on LTH is of great importance for finding a more effective approach to the prevention of cardiovascular mortality in a given cohort of patients. The presented review contains analysis of current literature data on the evaluation of both traditional and non-traditional risk factors for cardiovascular morbidity in order to improve the effectiveness of therapeutic and diagnostic tactics.
\end{abstract}

Keywords: Diabetes mellitus, vascular calcification, diabetic nephropathy, cardiovascular mortality, haemodialysis

\section{INTRODUCTION}

According to the latest data, the number of patients with diabetes in the world over the past 10 years has more than doubled, and according to the forecasts of the International Diabetes Federation, by the year 2,040, 642 million people will suffer from diabetes. In the Russian Federation, as in all countries of the world, there is a high rate of increase in the incidence of diabetes. The most dangerous consequences of the global epidemic of diabetes are its systemic vascular complications: diabetic nephropathy (DN), retinopathy, atherosclerotic lesions $^{[1]}$, which are the main cause of disability and mortality in patients with diabetes. According to the World Health Organization, more than $75 \%$ of patients with type 2 diabetes die due to vascular accidents ${ }^{[2]}$.

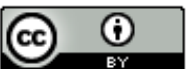

(C) The Author(s) 2018. Open Access This article is licensed under a Creative Commons Attribution 4.0 International License (https://creativecommons.org/licenses/by/4.0/), which permits unrestricted use, sharing, adaptation, distribution and reproduction in any medium or format, for any purpose, even commercially, as long as you give appropriate credit to the original author(s) and the source, provide a link to the Creative Commons license, and indicate if changes were made.

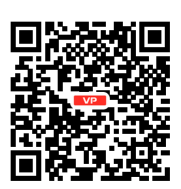


It is well known that patients with diabetes often have clinically proven ischemic heart disease (IHD) and heart failure (HF) compared to a group of the same age without diabetes ${ }^{[3-5]}$.

According to the American Heart Association, DN ranks second among the leading causes of death in patients with type 2 diabetes $^{[6]}$. In the United States and Japan, DN is most common among all kidney diseases (35\%-45\%), eclipsing such kidney pathologies as glomerulonephritis, polycystic kidney disease, pyelonephritis, etc. In Europe, the prevalence of DN is less threatening, but the demand for extracorporeal treatment continues to grow ${ }^{[7]}$.

According to the National Kidney Foundation of Japan (1998) there is a high prevalence of cardiovascular morbidity in patients with chronic kidney disease (CKD), and cardiovascular mortality is higher in dialysis patients than in the general population ${ }^{[8]}$.

Patients with CKD and diabetes are considered the highest risk group for the development of cardiovascular complications $^{[9]}$, which require appropriate preventive measures. The complex clinical profile of patients with diabetes on long-term hemodialysis (LTH) has prompted the search for new markers of cardiovascular risk, determined the tactics of therapy and the importance of prevention measures for cardiovascular complications. The purpose of the review is to analyze literature data on the evaluation of both traditional and non-traditional risk factors for cardiovascular morbidity in patients with diabetes on LTH, in order to find a more effective approach to therapeutic and diagnostic tactics.

\section{ATHEROSCLEROSIS, KIDNEY DISEASE AND CARDIOVASCULAR DISEASES IN PATIENTS WITH TYPE 2 DIABETES MELLITUS}

Atherosclerosis is a multifaceted disease, with traditional risk factors such as diabetes, obesity, dyslipidemia and hypertension, smoking and low physical activity.

Tanaka et al. ${ }^{[10]}$ showed that the low glomerular filtrate rate and proteinuria are independently associated with the development of atherosclerosis, which is facilitated by various pathogenetic mechanisms. CKD is a risk factor for the development of cardiovascular morbidity, and it also contributes to the development of dyslipidemia. Depending on the stage of the process, the nature of dyslipidemia in patients with CKD is different ${ }^{[11]}$. In the initial stages of CKD hypertriglyceridemia (HTG) develops because the enzymatic breakdown of triglycerides decreases due to a reduction in lipoprotein lipase activity.

CKD is also characterized by a decrease in the concentration of high-density anti-atherogenic lipoproteins (HDL), due to a low concentration and a decrease in the activity of lecithin-cholesterol acyltransferase, which leads to a disruption in the synthesis and transport of HDL and their accelerated degradation ${ }^{[12]}$.

It was shown that in patients with significant proteinuria and nephrotic syndrome, lipid metabolism disorders are associated with the increase of low-density lipoproteins (LDL), HTG and hypercholesterolemia ${ }^{[13]}$. Kato et al. ${ }^{[14]}$ showed that cardiovascular events are the main cause of death in patients on LTH. The index of intimamedia thickness (IMT) was significantly higher in patients who died from cardiovascular diseases and correlated with age and calcification of the aorta, showing the importance of measuring the IMT index as a predictor of the progression of cardiovascular mortality in patients on LTH.

Gluba et al. ${ }^{[15]}$ demonstrated that end-stage renal disease and type 2 diabetes are associated with the accelerated development of atherosclerosis. It was shown that atherosclerosis in the carotid and coronary arteries is an independent prognostic factor of mortality in patients with end-stage of $\mathrm{CKD}^{[16]}$. In DN and manifested atherosclerosis, altered LDL are detected, which undergo oxidative modification ${ }^{[17]}$. 


\section{MULTIPLE MODIFICATION OF LDL IN BLOOD PLASMA}

Modification of LDL occurs due to glycation, desialylation and oxidation of lipid and protein components of LDL, which, as shown in the studies, can eventually lead to their aggregation and the formation of immune complexes (IC). As a result, LDL become atherogenic, which increases their capture by macrophages and subsequent development of atherosclerosis. It was shown that modified LDL (m-LDL) are characterized by numerous changes in carbohydrate, protein and lipid constituent ${ }^{[18]} . \mathrm{m}-\mathrm{LDL}$, which were isolated from the blood of patients with IHD, are able to accumulate cholesterol and are atherogenic. It is indicated that $\mathrm{m}$-LDL undergo changes in a particle of lipoprotein, undergo desialylation, increase electronegative charge and become smaller and denser ${ }^{[19]}$. Desialylated LDL stimulate intracellular esterification of free cholesterol, which leads to the accumulation of cholesterol esters (cholesterol). When studying a number of chemical and physical parameters, a reliable inverse correlation was found between the atherogenic LDL and the content of sialic acid in them.

M-LDL are: cytotoxic for endothelial cells, chemotoxic for monocytes, inhibit the migration of macrophages; induce endothelial expression of macrophage colony-stimulating factor, which is the main regulator of macrophage survival, proliferation and differentiation; increase the synthesis of collagen in smooth muscle cells; inhibit lipopolysaccharide-induced expression of nuclear factor-kappaB; induce apoptosis; inhibit the release and/or functions of nitric oxide (vasospasm); increase the expression of adhesion molecules on blood vessels; increase the tissue factor activity in endothelial cells (which leads to thrombosis); cause the synthesis of a wide range of pro-inflammatory cytokines in macrophages; and cause an increase in circulating levels of antibodies ${ }^{[20]}$. Multiple modification of lipoprotein particles involves the formation of antigens against which antibodies can be formed ${ }^{[21]}$. It has been shown that in the blood of most patients with coronary atherosclerosis there are circulating IC, consisting of LDL and anti-LDL antibodies ${ }^{[22]}$. An increase in the level of $\mathrm{m}-\mathrm{LDL}$ and a high titer of antibodies to them in patients with diabetes with an existing cardiovascular pathology was revealed in comparison with the control group ${ }^{[23]}$.

Diabetes is a proven risk factor for developing atherosclerosis. Atherosclerotic vascular wall lesions progress in diabetes. Numerous data indicate that blood of type 2 diabetes mellitus (DM) patients contains m-LDL that undergo glycation. It provides non-enzymatic oxidation of LDL. It has been established that $\mathrm{m}$-LDL in the blood of patients with diabetes induce intracellular accumulation of cholesterol, which is associated with a different modification, both with desialylation and non-enzymatic glycation ${ }^{[2]}$.

Lankin et al. ${ }^{[24]}$ estimated the effect of the carbonyl modification of LDL on the properties of particles that determine their increased atherogenicity, such as the formation of intermolecular crosslinks in ApoB100, the oxidability of LDL particles and their ability for subsequent aggregation. With concomitant diabetes, a sharp progression of atherosclerotic vascular lesions was noted. In addition, it has been shown that the level of lipohydroperoxides in plasma LDL in patients with diabetes is 3 times higher than in patients with ischemic heart disease; it has also been demonstrated that desialylation is observed in the serum of patients with diabetes.

Borodachev et al. ${ }^{[25]}$ showed that in diabetic patients, the content of low-density lipoprotein cholesterolincreases, which produces a direct atherogenic effect, while $\mathrm{m}$-LDL have a small size, a greater density than the native ones, and carry an electronegative charge, i.e., become desialylated (have a reduced content of sialic acid) and glycated.

Bucala $e t$ al ${ }^{[26]}$ showed a significant increase in the level of the end products of glucose oxidation and the formation of $\mathrm{m}-\mathrm{LDL}$ in the blood of patients with diabetes and CKD compared with a healthy control group. 
Thus, hyperglycemia induces oxidative stress, which contributes to the accumulation of toxic products, which in turn leads to atherogenic modification of $\mathrm{m}$-LDL, endothelial dysfunction and atherosclerosis progression in patients with diabetes.

\section{NON-TRADITIONAL RISK FACTORS}

Non-traditional risk factors in patients with diabetes on LTH, which play a huge role in the development of vascular calcification (VC) and cardiovascular pathology in this group of patients, should not be overlooked.

CKD is more associated with non-traditional risk factors. They include impaired calcium-phosphate metabolism, which can lead to VC. VC was found in patients receiving long-term dialysis, who also demonstrated impaired calcium-phosphate metabolism ${ }^{[27]}$. Secondary hyperparathyroidism (SHPT), hypercalcemia and hyperphosphatemia are important links in the pathogenesis of VC in patients on LTH.

VC is a widespread complication of CKD and may lead to an increase in cardiovascular morbidity. VC is divided into two types according to the localization of calcifications: calcification of the inner membrane (intima) and the medial membrane (media) ${ }^{[28]}$. Calcification of the intima is associated with an atherosclerotic process. Risk factors for the development of atherosclerosis have been discussed above. Calcification of the media (mediacalcinosis, Menkberg sclerosis) is observed in patients on LTH in the absence of risk factors for atherosclerosis. The severity of VC may depend on many factors: the duration of hemodialysis therapy, the age and degree of disorders in calcium-phosphate metabolism ${ }^{[29]}$. In the works of Rumberger et al. ${ }^{[30]}$ hemodynamic consequences of VC are presented: loss of elasticity of arteries, increase in pulse pressure, development of left ventricular hypertrophy (LVH), HF, lower coronary artery perfusion and myocardial ischemia, which are the main causes of death of the majority of patients with CKD. According to Ribeiro et $\mathrm{al}^{[31]}$, the prevalence of calcification of the mitral and aortic valves (MVC and AVC) in patients on LTH is much higher than in the control group comparable in age and sex. Thus, according to the results of Kalpakian et al ${ }^{[32]}$, coronary artery calcification (CAC) was found in 53\%-92\% of patients with CKD. Raggi et al. ${ }^{[33]}$ showed that CAC is a predictor of cardiovascular morbidity in elderly patients with CKD. The degree of CAC was associated with male sex, diabetes and an increase in calcium-phosphate ratio.

It was revealed that CAC was much more common among patients on LTH, in comparison with patients without CKD. A possible reason for this may be impaired calcium-phosphate metabolism, rather than traditional risk factors, as previously believed ${ }^{[34,35]}$.

Komaba et al ${ }^{[36]}$, summarized the results of long-term follow-up study of patients on LTH, 38\% of whom had diabetes and had elevated levels of calcium (Ca), phosphorus (P), and intact parathyroid hormone (iPTH). Patients with $\mathrm{Ca}, \mathrm{P}$ and iPTH levels exceeding target ones showed the highest cardiovascular mortality.

Research by Bellasi et al. ${ }^{[37]}$ included patients with end-stage CKD. All patients underwent electron beam computed tomography (CT) for quantitative evaluation of CAC and calcification of the AVC on the Agatston scale. Calcification of heart valves was assessed by two-dimensional echocardiography (echo). As a result, the researchers concluded that patients who had valvular calcification or CAC had a higher risk of developing cardiovascular diseases. Lee et al. ${ }^{[38]}$ studied factors that are associated with the calcification of the aortic arch in patients on LTH. Calcification of the aortic arch was identified by X-ray. Patients were followedup for 10 years. The increase in calcification was associated with age, higher levels of $\mathrm{Ca}$ and blood glucose. During the follow-up period, the authors found that the degree of calcification of the aortic arch was directly related to cardiovascular mortality. According to the data of instrumental studies, Volkov et al ${ }^{[39]}$ have shown that coronary heart disease in $55.6 \%$ of patients and HF in $50.0 \%$ of patients on LTH. Combination of MVC and AVC was predominant. Valve calcification was more often observed in older patients, with longer dialysis treatment, more pronounced SHPT, inflammatory changes, and atherosclerosis. Calcification of 
valves was combined with a greater frequency of IHD, HF and dilatation of the left atrium ${ }^{[39]}$. Taking into account the research data, one can come to the conclusion that hyperphosphataemia, hypercalcemia and an, increase in the level of calcium-phosphate ratio are risk factors for the development of VC.

Other potential mechanisms of VC are associated with fibroblast growth factor-23 (FGF-23) and the activity of the transmembrane Klotho protein, which play an important role in the systemic regulation of phosphate homeostasis ${ }^{[40]}$.

FGF-23 is a protein consisting of 251 amino acids ( $32 \mathrm{kDa}$ molecular weight), which is secreted from osteocytes, mainly from osteoblasts ${ }^{[4]}$. FGF-23 exerts its biological effects through the activation of FGF receptors. FGF1s receptors, binding to the Klotho protein, become 1000 times more sensitive to interaction with FGF-23 than other FGF receptors or Klotho protein alone. Klotho is a $130 \mathrm{kDa}$ transmembrane protein. In the kidneys, FGF-23 induces phosphaturia, suppressing the expression of the sodium-phosphate cotransporter type IIa and IIc in the proximal tubule ${ }^{[42]}$.

The correlation between elevated levels of FGF-23 and adverse clinical outcomes in patients with CKD, such as cardiovascular morbidity and mortality ${ }^{[43]}$, has been shown. The relationship between an increase in the concentration of FGF-23 and the progression of CKD from stage I to V was revealed; a higher level of FGF-23 was observed in the group of patients on LTH. The same correlation was observed between the elevated FGF23 level in the blood serum and the Pourcelot resistive index (according to Doppler ultrasound) ${ }^{[44]}$. Jean et al ${ }^{[45]}$ obtained data indicating that mortality in dialysis patients is directly correlated with the level of FGF-23. Basic research of Grabner et al. ${ }^{[46]}$ convincingly showed that FGF-23 can directly lead to the development of LVH. The study revealed that the increase in FGF-23 led to LVH of de novo, and a high level of FGF-23 caused an increase in the frequency of LVH irrespective of the presence or absence of hypertension. FGF-23 causes LVH independently of the Klotho coreceptor, which is expressed predominantly in the kidneys and parathyroid glands and is absent in the cardiomyocytes. High levels of FGF-23 were also independently associated with endothelial dysfunction.

Inaba et al. ${ }^{[47]}$ studied the effect of FGF-23 on the development of aorta and peripheral artery calcification in men on LTH suffering from diabetes, and without diabetes. It was shown that an elevated level of FGF-23 in plasma in type 2 diabetes is significantly correlated with VC compared to patients without diabetes.

Chan et al. ${ }^{[48]}$, confirmed the link between an increase in FGF-23 concentration in plasma, diabetes and the calcification of coronary arteries.

Gutiérrez et al ${ }^{[49]}$ studied mortality associated with elevated levels of phosphorus and FGF-23 in patients on LTH. The researchers concluded that an elevated level of FGF-23 is independently correlated with mortality among patients on LTH. Studies put forward the main role of FGF-23 as a future biomarker of cardiovascular morbidity and mortality.

Hyperphosphatemia is one of the main risk factors for the development of cardiovascular pathology and mortality among patients with chronic renal failure.

Hyperphosphatemia directly associates with HF and cardiomyopathy, which can explain the direct correlation between phosphorus levels, cardiovascular morbidity and mortality. Hyperphosphatemia is associated with densification of the vascular wall, increased pulse wave velocity, LVH, decreased coronary blood flow and cardiovascular mortality ${ }^{[50]}$. In recent years, it has been proven that HF is an active and regulated process (similar to bone mineralization), in which various bone-related proteins participate. In addition to decreasing arterial compliance and their increased stiffness, hyperphosphatemia is closely 
involved in the mechanisms of development and progression of VC involving mineralization of vascular smooth muscle cells (VSMC) by phosphorus flux through sodium-dependent transporters, VSMC apoptosis. Cell death in the vascular wall leads to development of cell membrane debris and apoptotic cells, which can become the primary foci of apatite deposits. Increasing concentration of $\mathrm{P}$ and $\mathrm{Ca}$, on the one hand, leads to the growth of apatite crystals by passive precipitation, and on the other, can apparently activate cellular and tissue mechanisms of calcification: suppressing differentiation of monocytes/macrophages in osteoblast-like cells with increased FGF-23 levels and change in Klotho protein expression. Consequently, hyperphosphatemia and rebalancing inducers and inhibitors of calcification, the presence of systemic inflammation and oxidative stress contribute to the medial calcification in CKD. Osteogenic mechanisms involve changes in the phenotype of vascular wall cells. Proteins characteristic for bone tissue (osteopontin, osteocalcin, bone morphogenetic protein-2 (Run 2), as well as ectopic foci of typical bone and cartilage tissue formation were found in $\mathrm{VC}$ foci ${ }^{[51]}$.

A study of Kestenbaum ${ }^{[52]}$, conducted among patients with CRF, showed that the presence of phosphorus in the blood serum exceeding $3.5 \mathrm{mg} / \mathrm{dL}(1.13 \mathrm{mmol} / \mathrm{L})$ was associated with a significant increase of mortality risk, and for each increase of $1 \mathrm{mg} / \mathrm{dL}$ raised the risk of death by $18 \%$.

The CKD Outcomes and Practice Patterns Study showed that hyperphosphatemia (PO4 $>6.1 \mathrm{mg} / \mathrm{dL})$ was associated with an increase in total and cardiovascular mortality by $1.18^{[53]}$.

In $10 \%$ of participants in the 15 years prospective study it was noted that the initial level of serum phosphorus had a tight association with the calcification of the coronary arteries ${ }^{[54]}$. A close correlation of hyperphosphataemia and LVH has been identified, the development of which is a predictor of the CKD patients mortality.

When assessing the effect of elevated levels of PTH and calcium-phosphate product on cardiovascular mortality, Coen et al.$^{[55]}$ concluded that the mortality of patients on LTH is higher due to non-traditional risk factors.

It was shown that hyperphosphatemia is an independent factor determining the unfavorable prognosis, accelerating the progression of IHD, aggravating systolic hypertension and LVH, increasing the risk of arrhythmia, as well as acute and congestive HF in patients on $\mathrm{LTH}^{[56]}$.

\section{DIABETES MELLITUS AND VC}

Type 2 diabetes is one of the main independent risk factors for the development of cardiovascular pathology that is the cause of death of more than $60 \%$ of patients with type 2 diabetes ${ }^{[57]}$. In case of combined pathology (diabetes and atherosclerosis), the vascular wall is subject to changes that lead to a decrease in the effective lumen of the artery or thromboembolic complications.

However, in patients with diabetes in addition to atherosclerosis, calcification occurs. It was shown that the intensity of calcification increases in cases of diabetes, as confirmed by Peter Lanzer et al. ${ }^{[58]}$. Scientists have concluded that Menkeberg sclerosis is x4.5 time more likely to be present in women and x1.8 in men with diabetes than in individuals of appropriate age and sex who do not suffer from diabetes. Pathogenesis of VC in diabetes is similar to pathogenetic processes occurring in CKD.

Ishimura et al. ${ }^{[59]}$ compared the factors influencing the calcification of peripheral vessels in patients on longterm dialysis suffering from type 2 diabetes and without type 2 diabetes. It was revealed that the prevalence of VC in patients with diabetes was higher than in patients without diabetes. DM often combines with 
calcification of the arteries, the presence of which is a reliable marker of future cardiovascular events due to a combination of pathogenetic mechanisms in CKD and DM. There was also a high prevalence of CAC in patients with diabetes with CKD at stages $2-5^{[60]}$.

It was shown that patients with diabetes before dialysis have a greater risk of developing VC. CAC was calculated by CT. The prevalence of CAC and calcification of peripheral arteries were significantly higher in patients with diabetes and CKD at the pre-dialysis stage compared with the group of CKD stages 4-5 without diabetes ${ }^{[61]}$.

According to CT, the aortic calcification index was also significantly higher in patients with diabetes on hemodialysis than without diabetes ${ }^{[62]}$.

Qu et al ${ }^{[63]}$ studied the importance of coronary Ca according to CT in the development of cardiovascular morbidity and mortality in patients with diabetes for 6 years. They found that in patients with diabetes and coronary calcification, a fourfold increase in mortality was noted. It was concluded that the risk of developing cardiovascular pathology increases with the presence of diabetes, age and VC.

\section{CONCLUSION}

Thus, the analysis of literature data indicates a high occurrence of diabetes, especially in the terminal stage of CKD patients on LTH. At the same time, the influence of both m-LDL and atherosclerosis to LDL (traditional risk factors in the development of cardiovascular morbidity and mortality in patients), as well as FGF-23 and the Kloth protein, and P-Ca ratio (non-traditional factors) that contribute to VC in diabetes mellitus, which is very important the study of these changes will allow developing more optimal approaches to the prevention of cardiovascular morbidity and mortality in patients with diabetes complicated by DN.

\section{DECLARATIONS}

\section{Authors' contributions}

Selection of material and writing the text: Archakova T

Design and correction of the review: Nedosugova L

\section{Availability of data and materials}

Not applicable.

\section{Financial support and sponsorship}

None.

\section{Conflicts of interest}

All authors declared that there are no conflicts of interest.

\section{Ethical approval and consent to participate}

Not applicable.

\section{Consent for publication}

Not applicable.

\section{Copyright}

(C) The Author(s) 2018. 


\section{REFERENCES}

1. Consultant Doctor. Russian endocrinology clinical recommendations. Available from: http://www.rosmedlib.ru/book/ ISBN9785970436837.html. [Last accessed on 24 Oct 2018] (in Russian)

2. Foley RN, Culleton BF, Parfrey PS, Harnett JD, Kent GM, et al. Cardiac disease in diabetic end-stage renal disease. Diabetologia 1997;40:1307-12.

3. Tsujimoto T, Kajio H, Takahashi Y, Kishimoto M, Noto H, et al. Asymptomatic coronary heart disease in patients with type 2 diabetes with vascular complications: a cross-sectional study. BMJ Open 2011; doi: 10.1136/bmjopen-2011-000139.

4. Stamler J, Vaccaro O, Neaton JD, Wentworth D. Diabetes, other risk factors, and 12-yr cardiovascular mortality for men screened in the Multiple Risk Factor Intervention Trial. Diabetes care 1993;16:434-44.

5. Sarnak MJ, Levey AS, Schoolwerth AC, Coresh J, Culleton B, et al. Kidney disease as a risk factor for development of cardiovascular disease: a statement from the American Heart Association Councils on kidney in cardiovascular disease, high blood pressure research, clinical cardiology, and epidemiology and prevention. Circulation 2003;108:2154- 69.

6. Dedov II, Shestakova MV. Results of the implementation of the subprogram "diabetes mellitus of the federal target program" prevention and control of socially significant diseases 2007-2012. Available from: https://cyberleninka.ru/article/n/rezultaty-realizatsiipodprogrammy-saharnyy-diabet-federalnoy-tselevoy-programmy-preduprezhdenie-i-borba-s-sotsialno-znachimymi. [Last accessed on 24 Oct 2018] (in Russian)

7. Suzuki C, Nakamura S, Ishibashi-Ueda H, Yoshihara F, Kawano Y. Evidence for severe atherosclerotic changes in chronic hemodialysis patients: comparative autopsy study against cardiovascular disease patients without chronic kidney disease. Ther Apher Dial 2011;15:51-7.

8. Xue JL, Frazier ET, Herzog CA, Collins AJ. Association of heart disease with diabetes and hypertension in patients with ESRD. Am J Kidney Dis 2005;45:316-23.

9. Go AS, Chertow GM, Fan D, McCulloch CE, Hsu CY. Chronic kidney disease and the risks of death, cardiovascular events, and hospitalization. N Engl J Med 2004;351:1296-305.

10. Tanaka M, Yasaka M, Nagano K, Otsubo R, Oe H, et al. Moderate atheroma of the aortic arch and the risk of stroke. Cerebrovasc Dis 2006;21:26-31.

11. Sen S, Oppenheimer SM, Lima J, Cohen B. Risk factors for progression of aortic atheroma in stroke and transient ischemic attack patients. Stroke 2002;33:930-5.

12. Ku E, Campese V. Is lipid management effective for all stages of CKD? Blood Purif 2013;35:26-30.

13. Bhowmik D, Tiwari SC. Metabolic syndrome and chronic kidney disease. Indian J Nephrol 2008;18:1-4.

14. Kato A, Takita T, Maruyama Y, Kumagai H, Hishida A. Impact of carotid atherosclerosis on long-term mortality in chronic hemodialysis patients. Kidney Int 2003;64:1472-9.

15. Gluba A, Olechnowicz-Tietz S, Paradowska A, Banach M, Rysz J. The risk of atherosclerosis in patients with chronic kidney disease. Int Urol Nephrol 2013;45:1605-12.

16. Vaziri ND. Dyslipidemia of chronic renal failure: the nature, mechanisms, and potential consequences. Am J Physiol Renal Physiol 2006;290:F262-72.

17. Mutluay R, Degertekin CK, Poyraz F, Yılmaz MI, Yücel C, et al. Dialysis type may predict carotid intima media thickness and plaque presence in end-stage renal disease patients. Adv Ther 2012;29:370-82.

18. Ragino YI, Nikitin YP. Oxidized and structurally-modified low-density lipoproteins in atherosclerosis. Atherosclerosis 2006;2:3-32. (in Russian)

19. Stocker R, Keaney JF Jr. Role of oxidative modifications in atherosclerosis. Physiol Rev 2004;84:1381-478.

20. Medical Theses. Mechanisms and role of atherogenic modification of lipoproteins in atherogenesis. Available from: http://medical-diss. com/medicina/mehanizmy-i-rol-aterogennoy-modifikatsii-lipoproteidov-v-aterogeneze. [Last accessed on 24 Oct 2018] (in Russian)

21. Ylä-Herttuala S, Palinski W, Rosenfeld ME, Parthasarathy S, Carew TE, et al. Evidence for the presence of oxidatively modified low density lipoprotein in atherosclerotic lesions of rabbit and man. J Clin Invest 1989;84:1086-95.

22. Belova LA, Oglobina OG, Belov AA, Kukharchuk VV. Processes of modification of lipoproteins. Physiological and pathogenetical role of modified lipoproteins. Vopr Med Khim 2000;46:8-21. (in Russian)

23. Sukhorukov VN, Karagodin VP, Orekhov AN. Atherogenic modifications of low-density lipoproteins. Biomed Khim 2016;62:391-402. (in Russian)

24. Lankin VZ, Konovalova GG, Tikhaze AK, Nedosugova LV. The influence of glucose on the free radical peroxidation of low density lipoproteins in vitro and in vivo. Biomed Khim 2012;58:339-52. (in Russian)

25. Borodachev EN, Sobenin IA, Karagodin VP, Bobryshev Yu.V, Orekhov A. Multiple modification of low density lipoproteins in diabetes. Pathogenesis 2013;11:16-21. (in Russian)

26. Bucala R, Makita Z, Vega G, Grundy S, Koschinsky T, et al. Modification of low density lipoprotein by advanced glycation end products contributes to the dyslipidemia of diabetes and renal insufficiency. Proc Natl Acad Sci U S A 1994;91:9441-5.

27. Goodman WG, Goldin J, Kuizon BD, Yoon C, Gales B, et al. Coronary-artery calcification in young adults with end-stage renal disease who are undergoing dialysis. N Engl J Med 2000;342:1478-83.

28. Giachelli CM. Vascular calcification mechanisms. J Am Soc Nephrol 2004;15:2959-64.

29. Volgina G, Seleznev D, Balkarova O, Lovchinsky E. Extrinsic calcification in patients with CKD. Vrach 2012;7:2-8. (in Russian) 
30. Rumberger JA, Simons DB, Fitzpatrick LA, Sheedy PF, Schwartz RS. Coronary artery calcium area by electron-beam computed tomography and coronary atherosclerotic plaque area. A histopathologic correlative study. Circulation 1995;92:2157-62.

31. Ribeiro S, Ramos A, Brandão A, Rebelo JR, Guerra A, et al. Cardiac valve calcification in haemodialysis patients: role of calciumphosphate metabolism. Nephrol Dial Transplant 1998;13:2037-40.

32. Kalpakian MA, Mehrotra R. Vasgular calcification and disordered mineral metabolism in dialysis patients. Semin Dial 2007;20:139-43.

33. Raggi P, Boulay A, Chasan-Taber S, Amin N, Dillon M, et al. Cardiac calcification in adult hemodialysis patients. A link between endstage renal disease and cardiovascular disease? J Am Coll Cardiol 2002;39:695-701.

34. Bhan I, Thadhani R. Vascular calcification and ESRD: a hard target. Clin J Am Soc Nephrol 2009; doi: 10.2215/CJN.04800709.

35. Braun J, Oldendorf M, Moshage W, Heidler R, Zeitler E, et al. Electron beam computed tomography in the evaluation of cardiac calcification in chronic dialysis patients. Am J Kidney Dis 1996;27:394-401.

36. Komaba H, Igaki N, Takashima M, Goto S, Yokota K, et al. Calcium, phosphorus, cardiovascular events and all-cause mortality in hemodialysis patients: a single-center retrospective cohort study to reassess the validity of the Japanese Society for Dialysis Therapy guidelines. Ther Apher Dial 2008;12:42-8.

37. Bellasi A, Ferramosca E, Ratti C, Block G, Raggi P. Cardiac valve calcification is a marker of vascular disease in prevalent hemodialysis patients. J Nephrol 2012;25:211-8.

38. Lee CT, Chua S, Hsu CY, Tsai YC, Ng HY, et al. Biomarkers associated with vascular and valvular calcification in chronic hemodialysis patients. Dis Markers 2013;34:229-35.

39. Volkov MM, Degtereva OA, Shevyakova EV. Factors associated with calcification of valvular heart apparatus in patients on chronic hemodialysis. Available from: https:/cyberleninka.ru/article/n/faktory-svyazannye-s-kaltsinatsiey-klapannogo-apparata-serdtsa-upatsientov-na-hronicheskom-gemodialize. [Last accessed on 24 Oct 2018] (in Russian)

40. Cheng CY, Kuro-o M, Razzaque MS. Molecular regulation of phosphate metabolism by fibroblast growth factor-23- klotho system. Adv Chronic Kidney Dis 2011;18:91-7.

41. Riminucci M, Collins MT, Fedarko NS, Cherman N, Corsi A, et al. FGF-23 in fibrous dysplasia of bone and its relationship to renal phosphate wasting. J Clin Invest 2003;112:683-92.

42. Shimada T, Hasegawa H, Yamazaki Y, Muto T, Hino R, et al. FGF-23 is a potent regulator of vitamin D metabolism and phosphate homeostasis. J Bone Miner Res 2004;19:429-35.

43. Volgina G, Shtandel V, Balkarova O, Lovchinsky E. Hyperphosphatemia in chronic kidney disease: modern correction strategy. Vrach 2012;7:19-23. (in Russian)

44. Milovanova LY, Milovanov YS, Kozlovskaya LV, Mukhin NA. New markers of cardiorenal interrelations in chronic kidney disease. Therapeutic Archives 2013;6:17-24. (in Russian)

45. Jean G, Terrat JC, Vanel T, Hurot JM, Lorriaux C, et al. High levels of serum fibroblast growth factor (FGF)-23 are associated with increased mortality in long haemodialysis patients. Nephrol Dial Transplant 2009;24:2792-6.

46. Grabner A, Schramm K, Silswal N, Hendrix M, Yanucil C, et al. FGF23/FGFR4-mediated left ventricular hypertrophy is reversible. Sci Rep 2017;7:1993.

47. Inaba M, Okuno S, Imanishi Y, Yamada S, Shioi A, et al. Role of fibroblast growth factor-23 in peripheral vascular calcification in nondiabetic and diabetic hemodialysis patients. Osteoporos Int 2006;17:1506-13.

48. Chan GC, Divers J, Russell GB, Langefeld CD, Wagenknecht LE, et al. FGF23 concentration and APOL1 genotype are novel predictors of mortality in African Americans with type 2 diabetes. Diabetes Care 2018;41:178-86.

49. Gutiérrez OM, Mannstadt M, Isakova T, Rauh-Hain JA, Tamez H, et al. Fibroblast growth factor 23 and mortality among patients undergoing hemodialysis. N Engl J Med 2008;359:584-92.

50. Suliman ME, Stenvinkel P, Bárány P, Heimbürger O, Anderstam B, et al. Hyperhomocysteinemia and its relationship to cardiovascular disease in ESRD: influence of hypoalbuminemia, malnutrition, inflammation, and diabetes mellitus. Am J Kidney Dis 2003;41:S89-95.

51. Kardami E, Jiang ZS, Jimenez SK, Hirst CJ, Sheikh F, et al. Fibroblast growth factor 2 isoforms and cardiac hypertrophy. Cardiovase Res 2004;63:458-66.

52. Kestenbaum B, Sampson JN, Rudser KD, Patterson DJ, Seliger SL, et al. Serum phosphate levels and mortality risk among people with chronic kidney disease. J Am Soc Nephrol 2005;16:520-8.

53. Munoz Mendoza J, Isakova T, Cai X, Bayes LY, Faul C, et al. Inflammation and elevated levels of fibroblast growth factor 23 are independent risk factors for death in chronic kidney disease. Kidney Int 2017;91:711-9.

54. Rahman A, Gibney L, Person SD, Williams OD, Kiefe C, et al. Validity of self-reports of reasons for hospitalization by young adults and risk factors for discordance with medical records: the coronary artery risk development in young adults (CARDIA) study. Am J Epidemiol 2005;162:491-8.

55. Coen G, Manni M, Mantella D, Pierantozzi A, Balducci A, et al. Are PTH serum levels predictive of coronary calcifications in haemodialysis patients? Nephrol Dial Transplant 2007;22:3262-7.

56. Giachelli CM. Vascular calcification mechanisms. J Am Soc Nephrol 2004;15:2959-64.

57. Freedman BI, Divers J, Russell GB, Palmer ND, Bowden DW, et al. Plasma FGF23 and calcified atherosclerotic plaque in african americans with type 2 diabetes mellitus. Am J Nephrol 2015;42:391-401.

58. Lanzer P, Boehm M, Sorribas V, Thiriet M, Janzen J, et al. Medial vascular calcification revisited: review and perspectives. Eur Heart J 2014;35:1515-25.

59. Ishimura E, Okuno S, Kitatani K, Kim M, Shoji T, et al. Different risk factors for peripheral vascular calcification between diabetic and 
non-diabetic haemodialysis patients--importance of glycaemic control. Diabetologia 2002;45:1446-8.

60. Combe C, McCullough KP, Asano Y, Ginsberg N, Maroni BJ, et al. Kidney disease outcomes quality initiative (K/DOQI) and the dialysis outcomes and practice patterns study (DOPPS): nutrition guidelines, indicators, and practices. Am J Kidney Dis 2004;44:39-46.

61. Titan SM, Zatz R, Graciolli FG, dos Reis LM, Barros RT, et al. FGF-23 as a predictor of renal outcome in diabetic nephropathy. Clin J Am Soc Nephrol. 2011;6:241-7.

62. Palmer SC, Hayen A, Macaskill P, Pellegrini F, Craig JC, et al. Serum levels of phosphorus, parathyroid hormone, and calcium and risks of death and cardiovascular disease in individuals with chronic kidney disease: a systematic review and meta-analysis. JAMA 2011;305:1119-27.

63. Qu W, Le TT, Azen SP, Xiang M, Wong ND, et al. Value of coronary artery calcium scanning by computed tomography for predicting coronary heart disease in diabetic subjects. Diabetes Care 2003;26:905-10. 